\title{
Oxygenation at the onset of the Neoproterozoic - evidence from North China
}

YING ZHOU $^{1}$, ANIRBAN BASU ${ }^{2}$, ALEX DICKSON ${ }^{3}$, MAOYAN ZHU ${ }^{4}$ AND GRAHAM A SHIELDS ${ }^{1}$

${ }^{1}$ University College London

${ }^{2}$ Royal Holloway University of London

${ }^{3}$ Royal Holloway, University of London

${ }^{4}$ Nanjing Institute of Geology and Palaeontology

Presenting Author: y-zhou@ucl.ac.uk

The closing stages to the boring billion were originally suggested to have occurred around $\sim 0.8 \mathrm{Ga}$ with the "Bitter Springs" negative $\delta^{13} \mathrm{C}_{\text {carb }}$ anomaly. However, an earlier negative $\delta^{13} \mathrm{C}_{\text {carb }}$ excursion has been reported from Tonian strata on the Sino-Korean craton and named the Muckchon / Majiatun anomaly after units in North Korea and North China, respectively. Improved geochronology constrains its age to between c. 945 - $925 \mathrm{Ma}$ [1]. In this study, we report high resolution carbon isotope data from the Majiatun and neighbouring formations at two sections in the Dalian area of Liaoning Province. $\delta^{13} \mathrm{C}_{\text {carb }}$ values decrease from about $+4 \%$ to negative values over more than 100 metres of stratigraphy, reaching values as low as $-6 \%$, before recovering to positive values of up to $+4 \%$.

We additionally report new $\mathrm{Sr}$ and $\mathrm{U}$ isotope data from these same units. The $\mathrm{Sr}$ data can be correlated with our previously published record [2]. The change in seawater ${ }^{87} \mathrm{Sr} /{ }^{86} \mathrm{Sr}$ composition indicates a possible tie between ocean chemistry and weathering related to the final agglomeration of the supercontinent Rodinia. Negative carbon isotope excursions have been interpreted as ocean oxygenation events, potentially linked to such weathering, and the new $\delta^{238} \mathrm{U}$ results confirm fluctuations in seafloor anoxia with evidence for the earliest known ocean oxygenation event of the Neoproterozoic Era.

Combined with the increasing evidence for eukaryotic diversification around this time [3], and the mysterious 'Jinxian' biota [4] just after this perturbation, our study suggests an episodic and altogether more eventful end to the "boring billion".

[1] Su, X., et al.(2021). Lithos. 1-18.

[2]Zhou, Y., et al. (2020). Geology, 48: 462-467.

[3] Tang, Q et al. (2020). J. Nature ecology \& evolution, 4: 543-549.

[4] Luo et al. (2016). PalZ, 90, 205-224. 